\title{
Infantile Subdural Haematoma and its Relationship to Whiplash Injuries
}

\author{
A. N. GUTHKELCH
}

British Medical fournal, 1971, 2, 430-431

\section{Summary}

Subdural haematoma is one of the commonest features of the battered child syndrome; yet by no means all the patients so affected have external marks of injury on the head. This suggests that in some cases repeated acceleration/deceleration rather than direct violence is the cause of the haemorrhage, the infant having been shaken rather than struck by its parent. Such an hypothesis might also explain the remarkable frequency of the finding of subdural haemorrhage in battered children as compared with its incidence in head injuries of other origin, and the fact that it is so often bilateral.

\section{Introduction}

Subdural haematoma is a commoner complication of head injury in infancy than at any other age. Lewin (1966) reported 47 cases of subdural haemorrhage. in an unselected series of 1,750 head injuries occurring in patients of all ages-an incidence of about $2 \cdot 7 \%$-but Hendrick et al. (1964) found $5 \cdot 2 \%$ in a large series of head-injured children ranging in age from birth to 15 years, the excess over Lewin's series being entirely accounted for by a greatly increased frequency in infants aged under 2 years, and particularly in those under 6 months, in which latter group it was as high as $20 \%$. But there is no report of an incidence of subdural haematoma complicating road traffic accidents, etc., in very young children which approaches the $42 \%$ quoted by Weston (1968) in his series of necropsies of fatal cases of child assault, which is a particularly remarkable figure when one considers that the children in Weston's series ranged in age from 2 months to 5 years, with an average of 24 months - that is, considerably older than the high-risk group of Hendrick et al.- and that in some of them a head injury did not seem to have been noticed before death.

The commonest cause of infantile subdural haemorrhage is rupture of one or more of the delicate bridging veins which run from the cerebral cortex to the venous sinuses, the mode of injury being either a single acceleration or deceleration due to a heavy moving object striking the head or the rapidly moving head being brought up against a stationary mass; multiple applications of force would increase the total strain on the bridging veins and might result in an increased incidence of rupture. But direct violence is not an essential part of the picture. It has been known for some time that chronic subdural haematomas commonly occur in adults after disproportionately slight head injuries, sometimes when there is no reason to suppose that the head was ever injured at all. Meredith (1951) reported one such case in an adult after a fall on to the buttocks, and a senior American neurosurgeon (German et al., 1964) developed a subdural haematoma after his head had been jerked by the violent motion of the "bobsled" which he was riding at a fun fair.

Combined Neurological Service, Hull Royal Infirmary, Hull A. N. GUTHKELCH, M.CH., F.R.C.S., Consultant Neurosurgeon
More recently Ommaya and Yarnell (1969) published two welldocumented cases of subdural haematoma, in both of which the subject sustained a whiplash injury to the neck as a result of an automobile accident, the head itself not being injured at all. There was no immediate loss of consciousness and it was not until several days later that cerebral signs developed.

It is now submitted that the conditions which are known to exist in many cases of the battered child syndrome are particularly favourable to the production of subdural haematoma in infants by an essentially similar mechanism. Kempe et al. (1962) noted that in their experience the extremities of the child are often used as handles during an episode of rough treatment; "sometimes an arm is pulled to jerk a reluctant child to his feet, sometimes the legs are held while the tiny body is swung in a punitive way." In one of Caffey's (1946) cases of subdural haematoma the history is given in the following words: "Baby rolled off a table and his mother grabbed him by the forearm and jerked him in the air to prevent his fall." It seems clear that the relatively large head and puny neck muscles of the infant must render it particularly vulnerable to whiplash injury in this sort of situation. Moreover, since one would expect that the child is often grasped more or less symmetrically by chest or limbs the rotation-acceleration strains on the brain would tend to occur fairly symmetrically also, in an anteoposterior direction. This may be the reason why infantile subdural haematoma is even more of ten bilateral-for example, in 14 out of 18 cascs $(78 \%)$ in my carlicr scrics (Guthkelch, 1953)-than subdural haematoma in adults, for which the proportion of bilateral cases does not exceed $50 \%$.

One cannot say how commonly assault in the form of violent shaking rather than of direct blows on the head is the cause of subdural haematoma in infants who are maltreated by their parents. Possibly it will be found that the frequency of this mechanism varies between different nations according to their ideas of what is permissible, or at least excusable, in the treatment of children. Among the children mentioned in Weston's (1968) detailed records there were three-a 4-month-old girl, a 5-month-old boy, and a 2-year-old girl-in whom the cause of death was subdural haemorrhage, it being admitted by the assailant that the child had been violently shaken. In only one of these was there any mark of injury on the head, and this is described as a superficial bruise of the scalp, the baby's head having apparently struck the side of her cot, as it were, incidentally. Court (1969) quoted a mother's confession that she was in the habit of shaking her babies "in an insane rage."

\section{Patients}

Twenty-threc cases of proved or strongly suspected parental assault on children all under the age of 3 years, and all except one under 18 months, were admitted to the Hull Royal Infirmary between June 1967 and May 1970. Subdural bleeding had occurred in $13(57 \%)$ of these and was bilateral in 10, the only sort of injury which was recorded more of ten being bruising of the skin. One or more fractures of long bones were found in association with subdural haematoma in six cases.

There were eight children in whom a fracture of the skull was discovered, and six of these had a subdural haematoma. Of the seven children suffering from subdural haemorrhage who had no skull fracture five had no external marks of injury 
on the head either, though in one of these necropsy showed surface haemorrhages on the cerebral cortex, and another was found at operation to have extensive cortical bruising. Though 8 out of 16 battered babies with definite evidence of head trauma had a subdural haematoma, in 5 out of 13 cases of subdural haemorrhage no evidence of the application of direct violence to the head was forthcoming.

In two additional personal cases there was very strong reason indeed to suppose that the mechanism of production of the subdural haemorrhage had been by shaking rather than battering.

\section{CASE 1}

A 6-month-old boy was found by his father lying unconscious in his cot and having repeated convulsions. His mother was sitting beside him too shocked to speak or move. On admission to hospital he was found to be well nourished and well cared for, without any external marks of injury. He was stuporous and breathing heavily, with a temperature of $38^{\circ} \mathrm{C}$. There was pronounced hyperreflexia of all limbs and a tense fontanelle. Immediate subdural taps showed almost solid haematomas on both sides, but despite the evacuation of these he died three days later.

At necropsy several cortical bridging veins were found to have been torn from their dural attachments near the falx cerebri and the surface of the underlying brain was contused, with some small lacerations. There were no other internal injuries of any sort though some mucopus was present in the upper respiratory passages. The mother eventually admitted that the baby had had several fits of coughing and said that she feared that he was going to choke. She therefore held him up and shook him several times in order to try to clear his throat, whereupon he went into convulsions.

In this case the possibility of compression of the thorax with a consequent rise in jugular venous pressure and rupture of the cortical veins is not excluded, but there were no signs of bruising of the chest wall or of the lungs, nor any rib fractures. It was felt that the mother's account was probably truthful and that the tragedy occurred because of her lack of realization of the damage that can result from rough handling of a small baby. It has indeed been repeatedly observed that the parents of battered children may handle them exceedingly clumsily, even when they are under observation during their visits to hospital.

\section{CASE 2}

A 6-month-old boy was admitted to hospital on account of vomiting and convulsions, the suspected diagnosis being one of meningitis. Again there were no external signs of injury and no fractures of the skull or long bones, but the combination of a tense bulging fontanelle and bilateral retinal haemorrhages gave rise to a suspicion of subdural haematoma, which was confirmed and duly treated. At this time no suspicion of parental violence was entertained, but soon after his discharge from hospital the patient's twin brother was admitted suffering from a fracture of the femur for which his parents could give no explanation, and shortly afterwards the patient himself was readmitted with recurrent subdural haematomas on both sides. This time there were oval bruises on each of his forearms which fitted the pads of the fingers and thumb of the examiner's hand when the limbs were gripped. The parent denied having struck or beaten him but eventually his mother admitted that she and her husband "might have" shaken him when he cried at night.

\section{Comment}

The mere absence of visible injury on the head does not exclude direct violence, for Weston (1968) pointed out that in fatal cases "examination of the galea frequently revealed numerous ... haemorrhages .... even in the absence of conspicuous external bruising, abrasion or laceration." In a non-fatal case there is, of course, no opportunity to expose and examine the deep layers of the scalp, particularly now that craniotomy has been almost completely abandoned in the treatment of infantile subdural haematoma. None the less, one has the impression that "a good shaking," is felt, at least by British parents, to be socially more acceptable and physically less dangerous than a blow on the head or elsewhere.

As applied to the complicated mechanics of the brain and its coverings, subjected to the many different forces which constitute the causes of head injury, a limited series of experiments with a simple model proves nothing. Nevertheless, the following device, for the idea of which I am indebted to Dr. A. K. Ommaya, who has used a similar one to demonstrate the value of head restraint in preventing cerebral commotion in automobile accidents, may be found instructive.

An ordinary round-bottomed litre glass flask is filled with liquid paraffin in which have been suspended a few spoonsful of desicated coconut. When this mixture has been agitated the flakes will remain stationary in a state of even dispersion for periods of several minutes at a time. The flask is completely filled, closed with a rubber bung, and held firmly by the neck. It will be found that the flakes can be more readily set in motion, and will continue to swirl about for longer, after shaking for a few seconds than after the hardest blow that can be delivered without breaking the flask.

The phenomena observed are essentially similar to the movements of the brain which have been shown in anaesthetized monkeys in which the scalp and the top of the calvarium had been replaced by-a Perspex window and which were then subjected to sudden accelerations (Ommaya et al., 1968).

\section{Conclusion}

It has been shown that there is a discrepancy between the frequency of subdural haematoma occurring in battered children and of the same condition complicating head injuries of other origin, the incidence in the former being unexpectedly high, though in most of those in whom there was no actual skull fracture there was not even clear evidence of the application of direct violence to the head. This suggests that when the head is not the main target of attack the likely mechanism of production of the haematoma is one in which repeated sheering strains of one sort or another are applied to the cranial contents.

It follows that since all cases of infantile subdural haematoma are best assumed to be traumatic unless proved otherwise it would be unwise to disregard the possibility that one of these has been caused by serious violence, repetition of which may prove fatal, simply on the basis that there are no gross fractures or other radiological bone changes in the limbs, nor any fractures of the skull. One must keep in mind the possibility of assault in considering any case of infantile subdural haematoma, even when there are only trivial bruises or indeed no marks of injury at all, and inquire, however guardedly or tactfully, whether perhaps the baby's head could have been shaken.

I wish to acknowledge the co-operation of Dr. M. G. Philpott and Dr. R. J. Pugh, who permitted me to quote the series of battered children admitted under their care to Hull Royal Infirmary, and also of Mr. W. Tuffnell and Mr. L. Hodge, of Hull University, who prepared the model.

\section{References}

Caffey, J. (1946). American foumal of Roentgenology and Radium Therapy, 56, 163

Court, J. (1969). Medical Social Worker, 22, 15.

German, W. J., Flanigan, S., and Davey, L. M. (1964). Clinical Neurosurgery, 12, 344.

Hendrick, E. B., Harwood-Hash D. C. Fournal, 1, 233. Clinical Neurosurgery, 11, 46.

Kempe, C. H., Silverman, F. M., Steele, B. F., Droegemueller, W., and Silver, H. K. (1962). Fournal of the American Medical Association, 181, 17.

Lewin, W. (1966). The Management of Head Injuries, p. 77. London, Baillière, Tindall, \& Cassell.

Mcredith, J. M. (1951). Fournal of Neurosurgery, 8, 444.

Ommaya, A. K., Faas. F., and Yarnell, P. (1968). Foumal of the American Medical Association, 204, 285.

Ommaya, A. K., and Yarnell, P. (1969). Lancet, 2, 237.

Weston, J. T. (1968). In The Battered Child, ed. R. E. Helfer and C. H. Kempe, p. 77 and Appendix B, p. 227. Chicago, University of Chicago Press. 